\title{
Transparency as Inference: Reply to Alex Byrne
}

\author{
Markos Valaris \\ University of New South Wales
}

Much recent work on self-knowledge takes its cue from the following remark by Gareth Evans: "I get in a position to answer the question whether I believe that $p$ by putting into operation whatever procedure I have for answering the question whether $p$ " $(1982,225)$. Answering the question whether $p$ in the affirmative, in particular, is supposed to get one in a position to selfascribe the belief that $p$. But what exactly is the route that gets one from the first order belief that $p$ to a self-ascription of that belief, or to the second order belief which the self-ascription expresses?

In his article "Self-Knowledge and Transparency" in this journal, Alex Byrne argues that the route is inferential (Byrne 2011). Transparent self-knowledge, according to Byrne, involves an inference from world to mind; in particular, it involves an inference from the proposition that $p$ to the proposition that one believes that $p$ (a pattern which Byrne, following André Gallois (1996), calls the doxastic schema). ${ }^{1}$ In what follows I will argue that this is a mistake: transparent self knowledge does not involve such an inference.

Now, other critics of the inferential view have rested their objections on the fact that inferences from $p$ to the proposition that one believes that $p$ seem neither deductively valid nor inductively strong (for this objection, see Matt Boyle (2011)). However, this objection has proven inconclusive because, as Byrne points out, in the circumstances envisaged by him the inference is guaranteed to produce beliefs that are true, and safely so. My objection is different.

\footnotetext{
${ }^{1}$ Byrne has defended this view in the past too (Byrne 2005). Byrne makes it clear that his approach is meant to extend to mental states other than belief too. However, if the approach fails even in the central case of belief, it will fail in the same way in those other cases too.
} 
As I will argue, the problem with the inferential view is that the doxastic schema fails to meet an independently motivated necessary condition on rules of inference. ${ }^{2}$ In a nutshell, the problem is this: rules of inference must be applicable both categorically and hypothetically (for example, in reductio arguments). The doxastic schema, however, cannot be used in hypothetical reasoning. ${ }^{3}$

To see the problem, start by considering the rule of modus ponens, which allows one to infer $q$ from $p$ and if $p$ then $q{ }^{4}$ One can perfectly rationally employ the rule of modus ponens within the scope of an assumption, which one accepts merely for the sake of the argument. For example, the following seems like a perfectly rational piece of reasoning:

Step 1 Mary starts by making the assumption that creationism is true.

2 Rules of inference, in the sense relevant here, are rules that guide the mental activity of reasoning; they are not the rules of any formal system. I am not assuming that all reasoning must be captured by rules, and neither am I assuming that reasoning which is captured by rules must involve an explicit representation of the relevant rules.

${ }^{3}$ One might wonder whether the rule of necessitation in modal logic provides a counterexample to this. This, if true, would be especially damaging to my argument, as Byrne (2005, 95-96) has suggested that the doxastic schema should be thought of as analogous to formulations of the rule of necessitation which allow one to infer 'necessarily $p$ ' from $p$ alone. There is no problem for my argument here, however. Formulations of the rule of necessitation that allow one to infer 'necessarily $p$ ' from $p$ alone figure only in axiomatic systems, which do not allow for hypothetical proofs anyway. Versions of the rule of necessitation in natural deduction systems (which do allow for hypothetical proofs) involve as a premise not $p$ itself but rather something along the lines of the claim thatp has a proof without bypotheses, or is a theorem. They are not, therefore, analogous to Byrne's doxastic schema — and, not incidentally, they can be used within the scope of hypotheses of the form ' $p$ is a theorem'.

${ }^{4} \mathrm{I}$ am not assuming that every case in which one believes that $p$ and that if $p$ then $q$ is a case in which one would be rational to infer $q$. As many authors have noted, even deductively valid rules of inference are defeasible, in the sense that, given the right conditions, a subject would be irrational to reason in accordance with them. Given a sufficiently implausible $q$, for instance, one would be better off reconsidering one's commitment to $p$ or 'if $p$ then $q$ ' rather than believing $q$. However, the absence of defeating conditions is not an extra premise in one's reasoning: it is still from $p$ and 'if $p$ then $q$ ' that one infers $q$, not from these propositions and the proposition that no defeating conditions obtain. 
Step 2 Mary affirms (from background knowledge) that if creationism is true, then life on earth appeared some 6,000 years ago.

Step 3 Mary uses modus ponens to infer, within the scope of the assumption, that life on earth appeared some 6,000 ago.

Step 4 Mary affirms (from background knowledge) that life on earth did not appear some 6,000 years ago.

Step 5 Mary discharges the assumption, concluding (by reductio) that creationism is not true.

Now compare Mary's reasoning with the following: Step 1 Fred starts by making the assumption that creationism is true. Step 2 Fred uses the doxastic schema to conclude (within the scope of the assumption) that he believes that creationism is true.

Step 3 Fred affirms (from previous knowledge) that he does not believe that creationism is true.

Step 4 Fred discharges the assumption, concluding that creationism is not true. Fred's reasoning is obviously flawed. Equally obviously, the problem is in Step 2: Fred cannot conclude, within the scope of the assumption that creationism is true, that he believes that creationism is true. The doxastic schema, unlike modus ponens, is not available for hypothetical reasoning.

Being available for hypothetical reasoning is not a peculiarity of deductively valid rules of inference, like modus ponens. Formulating general rules for inductive reasoning is hard, but it seems clear that we do reason hypothetically with inductive rules, for otherwise activities such as contingent planning for the future would appear incomprehensible. If, while preparing for a hike in an unfamiliar area, Fred says "we should pack some extra water, for we might get lost", it is natural to take him to have reasoned from the hypothesis that we get lost to the conclusion 
that in such a situation we will need extra water. Such reasoning would seem to involve inductive rules, hypothetically applied.

Why is it that rules of inference must be available for hypothetical reasoning? I think we can begin answering this question by considering what is involved in applying a rule of inference categorically. Let us state rules of inference in the following way (the details of the formulation are immaterial to the argument):

\section{If conditions $C$ obtain, infer $p$.}

Consider a paradigmatic categorical application of the rule, i.e., one in which the subject knows that conditions $C$ obtain, and then comes to believe that $p$ as a result of applying the rule. Distinguish, now, between the subject's grounds for applying the rule and her attitude to those grounds. In the circumstances envisaged, the subject's grounds for applying the rule - and consequently for believing that $p$ - are simply that $C$ obtains, while her attitude to those grounds is knowledge. Crucially, from the point of view of the subject, what matters for the application of the rule is just that the grounds obtain (and that defeating conditions do not); her attitude to those grounds is not, for her, at issue in applying the rule. In the general case, inference is world-directed: the subject can infer $p$ on the grounds that $C$ without considering her own mental states at all. ${ }^{5}$

This feature of inference is what makes it the case that rules of inference must be available for hypothetical reasoning. Since, from the point of view of the subject, what matters for the application of the rule is just that conditions $C$ obtain, it must be possible for the subject to apply the rule while merely assuming for the sake of the argument that conditions $C$ obtain. In that

\footnotetext{
5 This point might be obscured by the common terminology of "basing". It is natural to describe Mrs. Hudson's belief that someone is at the door as based upon her hearing the doorbell ring (the example is from Byrne $(2005,94))$. It is clear, however, that Mrs. Hudson's grounds for believing that there is someone at the door consist simply in the doorbell's ringing, not in her hearing it do so. Her hearing it do so is merely an enabling condition of her inference, not part of her grounds.
} 
case, of course, applying the rule will not yield a belief that $p$, but merely lead the subject to accept $p$ for the sake of the argument.

These considerations allow us to give a deeper diagnosis of the problem with the inferential view of transparent self-knowledge. According to this view, in transparent selfknowledge the subject comes to believe that she believes that $p$ by inference from $p$. That is, she comes to believe that she believes that $p$ on the grounds that $p$. But this cannot be correct. It cannot be correct, because in that case it should be possible for the subject to make the same inference while merely assuming that $p$ for the sake of the argument. In other words, it should be possible to use the doxastic schema in hypothetical reasoning. Since we cannot use the doxastic schema in hypothetical reasoning, it follows that it is not the case that, in transparent selfknowledge, the subject believes that she believes that $p$ on the grounds that $p$. Transparent selfknowledge is not inferential.

So what should we say about the phenomenon of transparency? Although this is not the place to work out the details, I suggest that a constitutive approach might fare better. Suppose that believing that $p$ necessarily involves a disposition to believe that one believes that $p$ : first-order beliefs can play the role of second-order beliefs in our mental economy, given the right conditions. The notion of a disposition to believe intended here is roughly that of Robert Audi (1994). In order to be disposed to believe something in the relevant sense it is not sufficient for there to exist some circumstances — no matter how far-fetched — in which one would believe that thing. A disposition to believe is a special sensitivity to the object of the relevant belief: if the object of the belief is presented to one in the right way, one straightaway forms the belief. But then, it seems that judging that $p$ in the context of the transparency procedure should count as having one's belief that $p$ presented to one in a way fit to trigger a disposition to believe that one believes that $p$. Given our assumption that believing that $p$ involves having that disposition, judging that $p$ in the context of the transparency procedure straightaway results in believing that 
one believes that $p .{ }^{6}$ Crucially, one's grounds for the belief that one believes that $p$ do not consist in the proposition that $p$. One's grounds for that second-order belief consist in having one's belief that $p$ presented to one in the right way, in one's judgment that $p$. This, I suggest, suffices to explain why one's second-order belief counts as knowledge.

\section{References}

Audi, Robert. 1994. "Dispositional Beliefs and Dispositions to Believe." Noûs 28: 419-434.

Boyle, Matthew. 2011. "Transparent Self-Knowledge." Aristotelian Society Supplementary Volume 85: 223-241.

Byrne, Alex. 2005. "Introspection.” Philosophical Topics 33: 79-104.

. 2011. “Transparency, Belief, Intention.” Aristotelian Society Supplementary Volume 85: 201221.

Evans, Gareth. 1982. The Varieties of Reference. New York: Oxford University Press.

Gallois, André. 1996. The World Without, the Mind Within. Cambridge: Cambridge University Press.

\footnotetext{
${ }^{6}$ This is so regardless of whether following the transparency procedure leads one to retrieve an existing belief that $p$ from memory or to form a new belief that $p$ : in either case, the first-order belief will involve the disposition to believe that one believes that $p$, and that disposition will be triggered by one's explicitly judging that $p$.
} 